\title{
Optimization of Machining Process by Desirability Function Analysis (DFA): A Review
}

\author{
Pathalavathi Bhaskar ${ }^{1}$ and Sarat Kumar Sahoo ${ }^{2}$ \\ ${ }^{1}$ Asst. Professor, CVR College of Engineering/Mechanical Engg. Department, Hyderabad, India \\ Email: bhaskarnaik459@gmail.com \\ ${ }^{2}$ Asst. Professor, CVR College of Engineering Mechanical Engg. Department, Hyderabad, India \\ Email: saratkumar222@gmail.com
}

\begin{abstract}
The most essential goal of the optimization process is to minimize the cost and maximize the profit. In the case of industrial decision-making, optimization plays a major role. In the optimization process, the main target is to maximize 1 or some process parameters by keeping other parameters within constraints. Desirability function analysis (DFA), is a technique for the optimization of multiple response variables extensively used in the industry. DFA is based on the concept of the "quality" of the product or process having several quality characteristics. This method operates on the conditions which give the "most desirable" response values. In this review paper, the main concentration is on the optimization of a number of manufacturing processes which has been optimized by using DFA method. The previous review work by earlier researchers on the manufacturing process was not performed on such a large scale at a time on the DFA method by considering different processes. In the future, this review work can be worthwhile for the information at a single place for the succeeding researchers, in order to conclude their research work on the DFA technique.
\end{abstract}

Index Terms: Analysis, Optimization, Desirability function, DFA, Machining process

\section{INTRODUCTION}

Recently, manufacturing industries have attempted to introduce different optimization techniques to get the required specification of components with minimal input requirements. In order to achieve this, the operator of the machine has to choose suitable machining parameters. Optimization is a technique to maximize or minimize some function relative to some other set, representing a variety of choices accessible in a certain situation. The function allows in comparison of the various choices and to find out which might be the "best". In the manufacturing process, the outputs are maximized with the minimization of input parameters for higher productivity. Like, maximization of a number of products produced, increasing the quality of product and minimization of input material, minimization of time of production, minimization of cost production, etc. In manufacturing industries, usually multi-objective optimization is used for the overall growth of the industries for high production rates with a low cost of the product. By using a multi-objective optimization process all the outputs are optimized simultaneously and better quality products with a low cost are produced. Desirability function analysis (DFA) is one of the multi-objective optimization processes used for the optimization of different machining processes. It can be used for the optimization of more than one output parameter simultaneously $[1,2]$.
Desirability function analysis (DFA), is a technique for the optimization of multiple response variables extensively used in the industry. DFA is based on the concept of the "quality" of the product or process having several quality characteristics, with some of them out of "desired" limits that are completely unacceptable. This technique finds operating conditions $\mathrm{x}$, which provide the "most desirable" response values [1-4].

The following steps are used in DFA for optimization of the process parameters.

1st Step: Individual desirability index, 'di' for the corresponding responses can find out by using the formula given below. As per the response values, there are 3 types of desirability functions. i. Nominal - the best

$$
d_{i}=\left\{\begin{array}{c}
\left(\frac{y_{j}-y_{\min }}{T-y_{\min }}\right)^{s}, y_{\min } \leq y_{j} \leq T, s \geq 0 \\
\left(\frac{y_{j}-y_{\min }}{T-y_{\min }}\right)^{s}, T \leq y_{j} \leq y_{\max }, s \geq 0 \\
0
\end{array}\right.
$$

' $y_{j}$ ' is necessary to get desired target $T$. Desirability value becomes 1, when ' $y$ ' equals to $T$. Desirability value becomes 0 , when ' $y$ ' exceeds a particular range from the target and that situation indicates the worst case. Here, 's' is the weightage value whose value normally taken as 1 .

\section{ii. Larger-the better}

Larger the value of ' $y_{j}$ ', is expected to be better than the overall characteristics. When ' $y$ ' exceeds a specific value, the desirability value becomes 1 . When ' $y$ ' value falls below a specific value, the desirability value becomes 0 , which is unacceptable.

$$
d_{i}=\left\{\begin{array}{c}
0, y_{j} \leq y_{\min } \\
\left(\frac{y_{j}-y_{\min }}{y_{\max }-y_{\min }}\right)^{r}, y_{\min } \leq y_{j} \leq y_{\max }, r \geq 0 \\
1, y_{j} \geq y_{\min }
\end{array}\right.
$$

iii. Smaller-the better

$$
d_{i}=\left\{\begin{array}{c}
1, y_{j} \leq y_{\min } \\
\left(\frac{y_{j}-y_{\max }}{y_{\min }-y_{\max }}\right)^{r}, \quad y_{\min } \leq y_{j} \leq y_{\max }, r \geq 0 \\
0, y_{j} \geq y_{\min }
\end{array}\right.
$$

Smaller the value of 'yj', is expected to be better the overall characteristics. When ' $y$ ' value falls below a specific 
value, the desirability value becomes 1 . When ' $y$ ' exceeds a specific value, the desirability value becomes 0 , which is unacceptable. "Smaller the better" and "larger the better" characteristics are applied to calculate the individual desirability values to minimize or maximize the response. Here, ' $r$ ' is the weightage value whose value is normally taken as 1 .

$2^{\text {nd }}$ Step: Overall desirability, ' $\mathrm{d}_{0}$ ' can be calculated by using the ' $\mathrm{d}_{\mathrm{i}}$ ' values of all responses. This is done by using the formula given below. Here, w1, w2, w3 etc. are the weight factor whose summation is equal to 1 .

$$
d_{0}=\sqrt[w]{\left(d_{1}^{w 1} \times d_{2}^{w 2} \cdots \cdots d_{i}^{w i}\right)}
$$

3rd Step: In this step, we need to find out the optimal parameter and its level sequence. Higher ' $d 0$ ' value suggests a better quality product. Hence, the optimum level of each parameter can find out by using the ' $\mathrm{d} 0$ ' value.

In the manufacturing process, the raw material is converted into the final product by various processes, namely joining of materials, removal of unwanted materials (i.e. Machining), by deforming the materials, melting of materials, etc. Presently, traditional machining processes are used along with non-traditional machining processes to make the product from the bulk material to the final product. In this review work, the following machining processes are considered.

Turning is a material removal process, where the undesired material is removed with the help of a single-point cutting tool (point contact with the workpiece). Here, cutting forces are applied through the cutting edge to the workpiece for the removal of material. Turning is the most commonly used machining process used in industries.

Drilling is a process where a multi-point cutting tool is used for the removal of unwanted materials in order to produce the desired hole. This process is mainly used to create cylindrical holes in a workpiece. Similarly, Laser drilling is the process of drilling holes with the help of a laser source. The laser is also used for a curve cutting of parts to make it to the final product. In milling process, a multi-point cutting tool in form of a rotary cutter is used to remove materials from. The important cutting parameter in milling operation includes the cutting velocity, feed per tooth and depths of cut (radial and axial).

EDM (i.e. Electric discharge machining) is a spark machining process to produce the desired shape of components by using electrical discharges (sparks). Similarly, wire-EDM is used to cut the components by using wire as a tool with the use of electrical discharges (sparks).

For all the machining process, a number of factors are associated, which can be optimized for better results.

\section{Optimization Of Machining Processes by DESIRABILITY FUNCTION ANALYSIS (DFA)}

Aggarwal et al. [1] have studied the turning process of AISI P-20 steel metal by using the cryogenic cutting environment of with coolant of liquid nitrogen and by changing four controllable factors namely; feed, cutting speed, depth of cut, and nose radius. RSM technique used for modelling of the response variables and face centred central composite design was used for the experiment. They have optimized multiple output parameters namely; surface roughness, cutting force, power consumption and tool life by using the desirability of function technique.

Bara et al. [2] have studied Nd:YAG laser micro drilling of the workpiece (304 stainless steel) by varying input parameters namely; nitrogen gas pressure, nozzle standoff distance, and average power consumption. They have optimized output parameters of laser micro-drilling like entry circularity, taper angle and exit circularity by desirability function approach. They found that, for laser drilling maximum contribution percentage shared by ' $\mathrm{N} 2$ ' gas pressure and nozzle stand-off distance i.e. $54.62 \%$ and $27.69 \%$ respectively towards the overall output parameters (overall desirability). But, average power contribution is the lowest i.e. $2.98 \%$ towards overall output parameters. Figure 1 shows the percentage contribution of input parameters on the overall desirability index

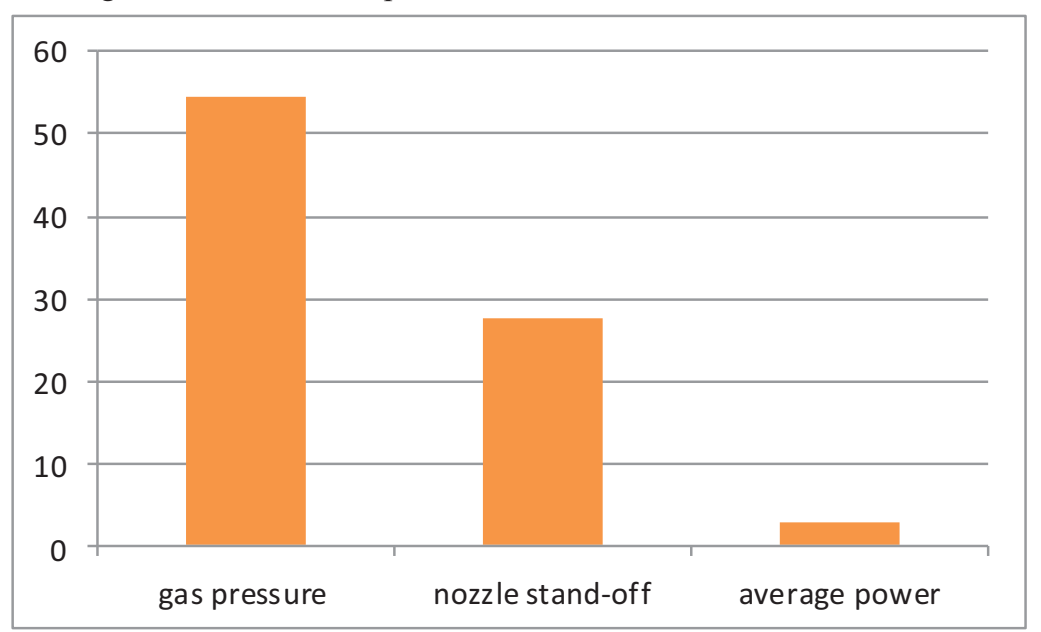

Figure 1. Percentage contribution of input parameters on overall desirability index in laser drilling [2] 
Sahu et al. [3] have studied electro-discharge machining (EDM) of nitinol by taking different tools and varying the EDM input parameters and optimized the output surface parameters namely; max. Profile height, avg. roughness and avg. profile height by using DFA technique. Percentage contribution of tool type, duty cycle, current and voltage on overall performance are; 61.98, 10.94, 3.79 and 2.79 respectively, which is shown in Fig. 2.

Kamguem et al. [4] have studied the surface roughness and emission of metallic particles during the milling process of aluminum alloys (2024-T351, 6061-T6, 7075-T6) with two coated carbide tools ( $\mathrm{TiCN}, \mathrm{TiCN}+\mathrm{Al}_{2} \mathrm{O}_{3}+\mathrm{TiN}$ ). The varying input parameters are speed, feed,depth of cut, coated inserts and type of workpiece material. RSM technique is used to perform the experiments and DFA technique is used to optimize the output. dalarasan and Santhanakumar [5] have studied wire-EDM of Al6351/20\%Al2O3 composite workpiece by using copper wire by varying input parameters voltage, capacitance, feed and tension of the wire. RSM technique is used to perform the experiments and DFA technique is used to optimize the output.

Assarzadeh and Ghoreishi [6] have studied electric discharge machining of aluminum oxide (A12O3) powder mixed in kerosene dielectric in machining of CK45 die steel by the use of the copper tool. RSM technique with FCC composite design model is used to perform the experiments. Current, voltage \& pulse on time are input parameters that vary during the process. DFA technique is used to optimize the output parameters like MRR (material removal rate) and surface

finish.

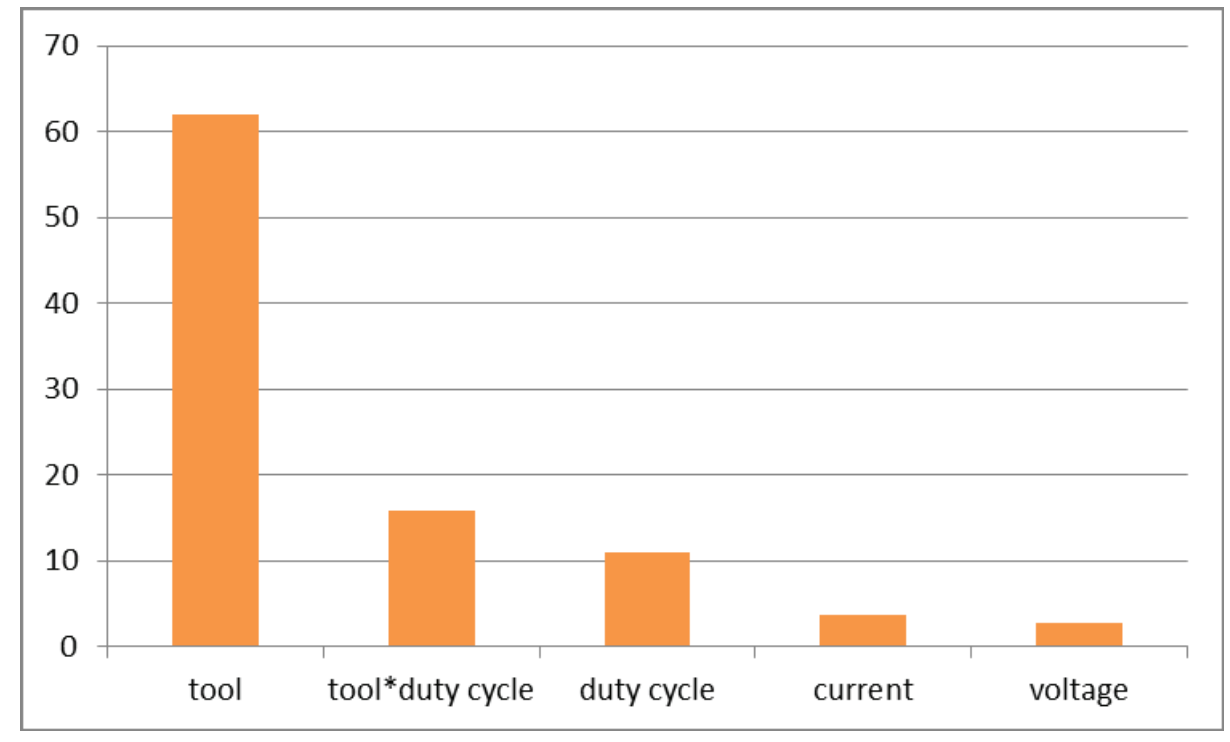

Figure 2. Contribution \% of individual input parameters on overall desirability index in EDM [3]

Garg et al. [7] have studied the machining of Aluminium with $\mathrm{ZrO} 2$ metal matrix composite by wire-EDM process by varying input parameters pulse on time, pulse gap, servo voltage, wire feed rate and wire tension by the use of RSM with central composite design. Desirability function technique is applied to optimize the wire-EDM process parameters namely; cutting velocity \& surface finish.

Gopalakannan and Thiagarajan [8] have studied the EDM of Al 7075 alloy by using copper tool based on a central composite design by changing input parameters namely; pulse on time, pulse off time, voltage $\&$ current. They have studied the performance of the process by taking the output as electrode wear rate, material removal rate \& surface roughness. Desirability function technique is applied to optimize the output of the EDM process parameters simultaneously. The ramp function graph of the desirability index for the EDM process $\mathrm{Al}+10 \mathrm{wt} \% \mathrm{SiC} \mathrm{MMC}$ is shown in Fig. 3.

Kumar et al. [9] have performed wire-EDM of Monel-400 by varying input parameters namely; pulse on time, pulse off time, current and servo voltage. The experimental design based on RSM with face centered central composite design.
The output responses namely; machining rate and surface finish have been studied. The desirability function technique is applied to optimize the response parameters.

Kumar et al. [10] have performed wire cut EDM operation of titanium workpiece material by considering the varying input parameters as pulse-on time, pulse-off time, current, voltage, wire tension \& wire feed rate. The experimental design is based on the RSM Box-Behnken technique. The output responses taken into consideration are MRR and overcut. The desirability function technique is applied to optimize the response parameters. The multiresponse optimization to maximize MRR and minimize overcut during wire cut EDM of titanium by using DFA is shown in Fig. 4.

Mythuraman and Ramakrishnan [11] have studied wireEDM of WC-Co composites by using zinc-coated copper wire. They have studied effect of input parameters namely; percentage of Co, current, wire tension, pulse on time, delay time, wire feed, and dielectric fluid pressure on the output parameters like material removal rate and surface roughness. The $\mathrm{o} / \mathrm{p}$ responses are optimized by the desirability function approach. 
Pandey and Panda [12] have studied bone drilling by using high speed steel (HSS) drill bit by varying inputs feed rate and spindle speed. They have considered the outputs temperature and thrust force and optimized for the minimization the outputs by using desirability function approach.

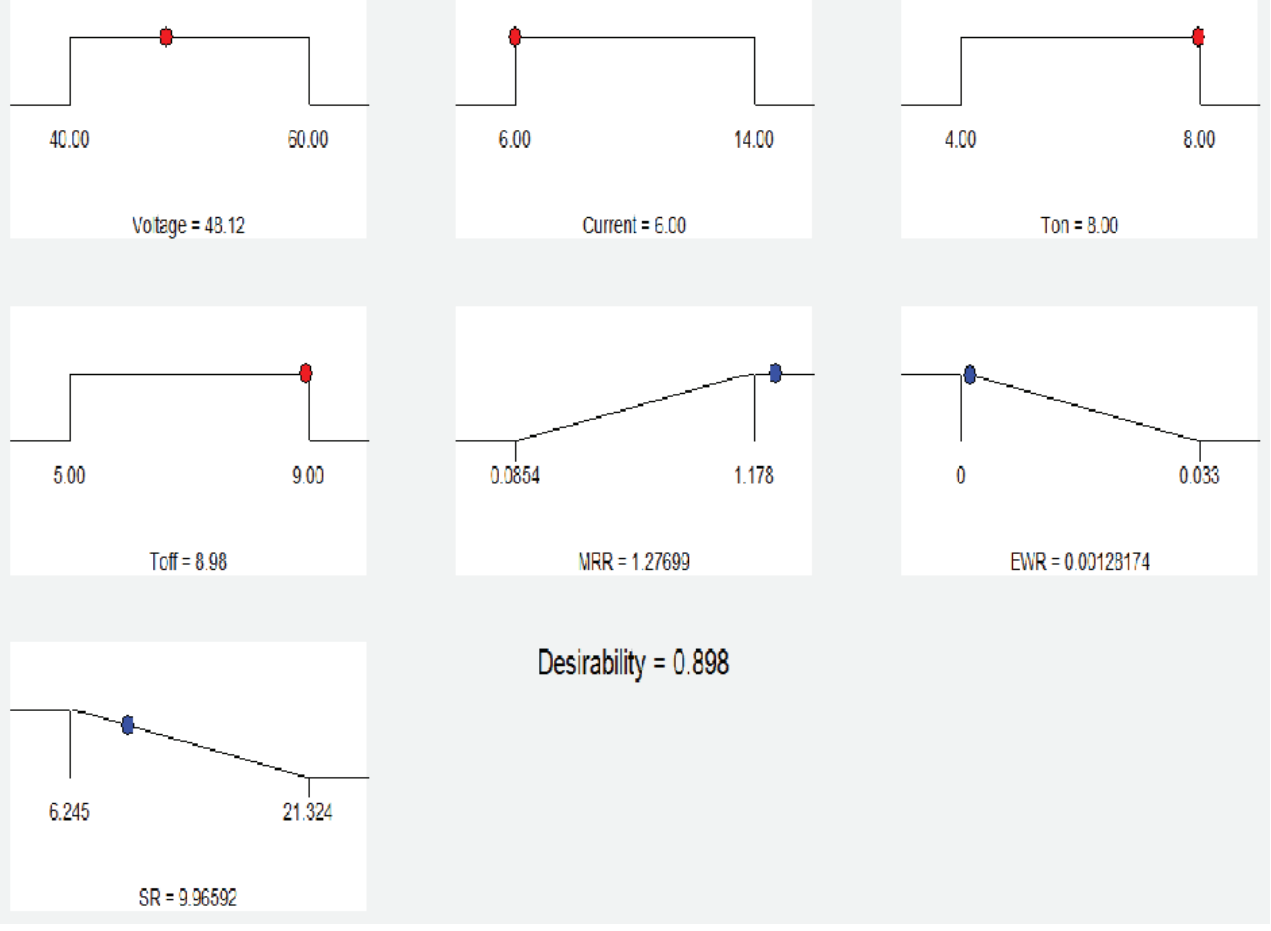

Figure 3. Ramp function graph of desirability index for EDM process [8]

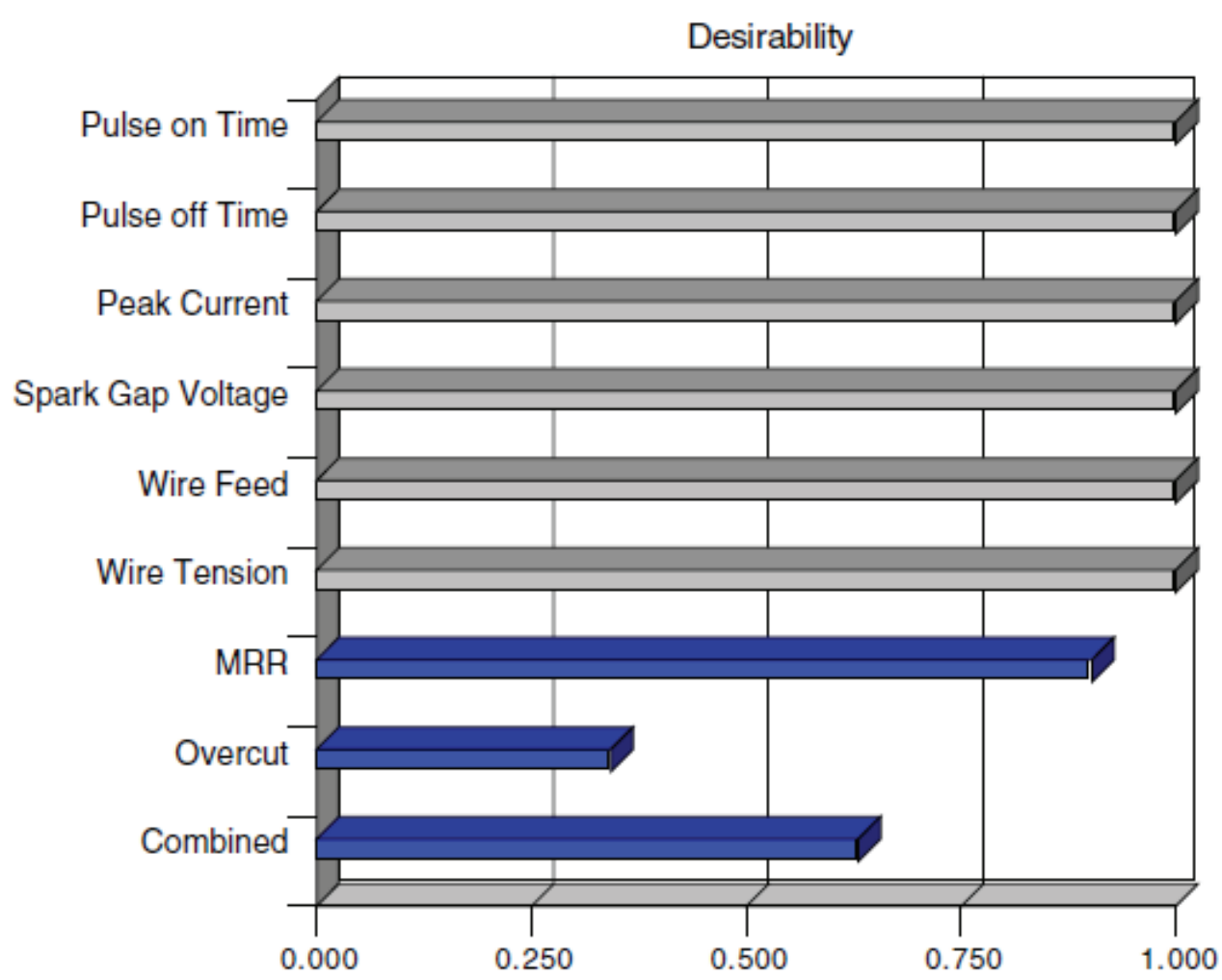

Figure 4. Multi response optimization result for maximum MRR and minimum overcut using DFA [10] 
Pandey and Panda [13] have studied bone drilling by using high speed steel drill by varying inputs feed rate and spindle speed. They have considered the outputs parameters as; maximum force, maximum temperature and average surface roughness. The responses are optimized for the minimization of the outputs by the help of fuzzy based desirability function technique.

Prakash et al. [14] have studied the drilling of medium density fiberboards and optimized delamination factor by desirability function approach.

Ramanujam et al. [15] have studied end milling of Inconel alloy by changing input parameters like feed, speed and depth of cut. They have optimized the end milling process by considering output parameters as surface roughness and MRR by using desirability function approach.

Sahu and Mahapatra [16] have optimized electric discharge machining of titanium alloy by using desirability function approach. They have considered the output parameters as maximum profile height, average roughness and avg. profile height.

Sait et al. [17] have studied the machining of glass fiber reinforced plastic (GFRP) pipes by the use of coated carbide tool K20 inserts. They have considered input parameters as cutting velocity, feed rate and depth of cut with consideration of output parameters as flank wear, crater wear, force and surface roughness. Taguchi method is used for the design of the experiment and desirability function analysis using optimization of the machining process.

Selaimia et al. [18] have studied in dry face milling of austenitic stainless steel by varying parameters as, cutting speed, feed and depth of cut. The output parameters considered are surface finish, cutting force, and MRR. RSM technique is used for the design and statistical analysis of data. Desirability function method used to optimize the process parameters.

Sengottuvel et al. [19] have studied the EDM of Inconel 718 by the help of copper electrode of different tool shapes like circular, square, rectangular and triangular shape. They have optimized the EDM process by using desirability function technique and fuzzy modeling by considering MRR, TWR and surface smoothness as output parameters.

Sharma and Kumar [20] have studied laser curve cutting of composites Aluminium metal by taking inputs parameters as speed of cutting, power of laser, gas pressure, stand-off distance, nozzle diameter, $\mathrm{SiC}$ reinforcement and arc radius. They have optimized the process by desirability function approach considering surface finish and kerf deviation as $\mathrm{o} / \mathrm{p}$ parameters.

Sharma et al. [21] have examined turning of GFRP composite materials and applied Fuzzy logic modeling and multi-objective optimization of desirability function analysis. The response process parameters are MRR, TWR $\&$ surface roughness.

PSingaravel and Selvaraj [22] have studied turning of EN25 steel metal by CVD and PVD coated carbide tool inserts. The input machining parameters are coated tools, feed, cutting speed and depth of cut. The response variables are MRR, cutting force and surface irregularity. They have optimized the machining process by desirability function analysis.

Vasudevan et al. [23] have studied drilling characteristics of epoxy composite materials by varying input parameters speed of spindle, feed rate, the thickness of the material and drill size. They have optimized the drilling by desirability coupled with Taguchi method for multi-objective optimization by taking output parameters as delamination factor and surface roughness.

\section{SUMMARY}

In this review work, desirability function analysis (DFA) one of the prominent optimization techniques has been summarized especially in relation to the manufacturing processes. This method is simple and involves less number of computational steps as compared to other multi-objective optimization techniques. In this study, the application of the desirability function technique for the optimization of multicriteria optimization problems is analyzed by taking the literature of previous researchers. The DFA has the potential for the optimization of the multi-objective optimization process for different manufacturing processes such as electro-discharge machining, wire-electro-discharge machining, turning, milling, drilling, and laser drilling of different materials. The DFA can be well suitable in manufacturing industries for optimization of the machining process to get higher output with minimization of input parameters for their growth of manufacturing industries in today's competitive market.

\section{REFERENCES}

[1] G Aman Aggarwal, Hari Singh, Pradeep Kumar and Manmohan Singhd, "Optimization of multiple quality characteristics for $\mathrm{CNC}$ turning under cryogenic cutting environment using desirability function" journal of materials processing technology, vol. 205, pp. 42-50, 2008.

[2] Alok Bara, Sarat Kumar Sahoo, Sunita Sigh Naik, Anshuman Kumar Sahu and Siba Sankar Mahapatra, "Multi Response Optimization of Nd:YAG Laser Micro Drilling Characteristics of 304 Stainless Steel using Desirability Function Approach", Materials Today: Proceedings, Vol. 5, pp. 18975-18982, 2018.

[3] Anshuman Kumar Sahu, Suman Chatterjee, Praveen Kumar Nayak and Siba Sankar Mahapatra, "Study on effect of tool electrodes on surface finish during discharge machining of Nitinol", IOP Conf. Series: Materials Science and Engineering, Vol. 338, 2018.

[4] R. Kamguem, A. Djebara and V. Songmene, "Investigation on surface finish and metallic particle emission during machining of aluminum alloys using response surface methodology and desirability functions", Int J Adv Manuf Technol, Vol. 69, pp. 1283-1298, 2013.

[5] R. Adalarasan and M. Santhanakumar, "Response Surface Methodology and Desirability Analysis for Optimizing $\mu$ WEDM Parameters for A16351/20\% Al2O3 composite", International Journal of ChemTech Research, CODEN (USA): IJCRGG ISSN: 0974-4290, Vol.7, No.6, pp. 2625-2631, 2014-2015. 
Al2O3 powder-mixed electrical discharge machining (PMEDM) parameters, Int J Adv Manuf Technol, Vol. 64, pp.1459-1477, 2013.

[7] Sanjeev K. Garg, Alakesh Manna and Ajai Jain, "An Investigation on Machinability of $\mathrm{Al} / 10 \% \mathrm{ZrO} 2(\mathrm{P})-$ Metal Matrix Composite byWEDM and Parametric Optimization Using Desirability Function Approach", Arab J Sci Eng, Vol. 39, pp.3251-3270, 2014

[8] Subramanian Gopalakannan and Thiagarajan Senthilvelan, "Optimization of machining parameters for EDM operations based on central composite design and desirability approach", Journal of Mechanical Science and Technology, Vol. 28, pp. 1045-1053, 2014.

[9] Vinod Kumar, Vikas Kumar and Kamal Kumar Jangra, “An experimental analysis and optimization of machining rate and surface characteristics in WEDM of Monel-400 using RSM and desirability approach", J Ind Eng Int, Vol. 11, pp.297307, 2015.

[10] Anish Kumar, Vinod Kumar and Jatinder Kumar, "Semiempirical model on MRR and overcut in WEDM process of pure titanium using multi-objective desirability approach", J Braz. Soc. Mech. Sci. Eng., Vol. 37, pp. 689-721, 2015.

[11] V. Muthuraman and R. Ramkrishnan, "Multi Parametric Optimization of WC-Co Composites using Desirability Approach", Procedia engineering, Vol. 38, pp. 3381-3390, 2012.

[12] Rupesh Kumar, Pandey and S. S. Panda, "Optimization of Bone Drilling Process with Multiple Performance Characteristics Using Desirability Analysis", APCBEE Procedia, Vol. 9, pp. 48 - 53, 2014.

[13] Rupesh Kumar Pandey and S. S. Panda, "Optimization of bone drilling using Taguchi methodology coupled with fuzzy based desirability function approach", J Intell Manuf, Vol. 26, pp.1121-1129, 2015.

[14] S. Prakash, K. Palanikumar and N. Manoharan, "Optimization of delamination factor in drilling medium-density fiberboards (MDF) using desirability-based approach", Int J Adv Manuf Technol, Vol. 45, pp.370-381, 2009.

[15] R. Ramanujam, Lohithaksha M. Maiyar, K. Venkatesan and Mithun Vasan, "multi-response optimization using anova and desirability function analysis: a case study in end milling of inconel alloy", ARPN Journal of Engineering and Applied Sciences, Vol. 9, NO. 4, 2014.

[16] Anshuman Kumar Sahu and Siba Sankar Mahapatra, "Optimization of Surface Roughness Parameters by Different Multi-Response Optimization Techniques During ElectroDischarge Machining of Titanium Alloy, DOI: 10.4018/9781-5225-6161-3.ch004, 2019.

[17] A. Naveen Sait, S. Aravindan and A. Noorul Haq, "Optimisation of machining parameters of glass-fibrereinforced plastic (GFRP) pipes by desirability function analysis using Taguchi technique", Int J Adv Manuf Technol, Vol. 43, pp.581-589, 2009.

[18] Abdel-Ali Selaimia, Mohamed Athmane Yallese, Hamza Bensouilah, IKhlas Meddour, Riad Khattabi and Tarek Mabrouki, "Modeling and optimization in dry face milling of X2CrNi18-9 austenitic stainless steel using RMS and desirability approach", Measurement, Vol. 107, pp. 53-67, 2017.

[19] Sengottuvel.P, Satishkumar.S and Dinakaran.D, "Optimization Of Multiple Characteristics Of EDM Parameters Based On Desirability Approach And Fuzzy Modeling”, Procedia Engineering, Vol. 64, pp. 1069 - 1078, 2013

[20] Vikas Sharma and Vinod Kumar, "Multi- objective optimization of laser curve cutting of aluminium metal matrix composites using desirability function approach”, J Braz. Soc. Mech. Sci. Eng., Vol. 38, pp.1221-1238, 2016.

[21] Shiv Sharmaa, Santosh Tamanga, D.Devarasiddappab and M.Chandrasekran, "Fuzzy logic modeling and multiple performance optimization in turning GFRP composites using desirability function analysis", Procedia Materials Science, Vol. 6, pp. 1805 - 1814, 2014

[22] B. Singaravel and T. Selvaraj, "Application of Desirability Function Analysis and Utility Concept for Selection of Optimum Cutting Parameters in Turning Operation", Journal of Advanced Manufacturing Systems, Vol. 15, No. 1, pp. 111, 2016.

[23] Hari Vasudevana, Ramesh R. Rajgurub, Naresh and Deshpande, "Multiobjective Optimization of Drilling Characteristics for NEMA G-11 GFRP/Epoxy Composite using Desirability coupled with Taguchi Method", Procedia Engineering, Vol. 97, pp. 522 - 530, 2014. 